\title{
Article \\ Comparison of Novel Biochars and Steam Activated Carbon from Mixed Conifer Mill Residues
}

\author{
Nathaniel Anderson 1,*, Hongmei Gu ${ }^{2}$ (D) and Richard Bergman ${ }^{2}$ (D) \\ 1 United States Forest Service, Rocky Mountain Research Station, 800 East Beckwith Avenue, \\ Missoula, MT 59801, USA \\ 2 United States Forest Service, Forest Products Laboratory, 1 Gifford Pinchot Drive, Madison, WI 53726, USA; \\ hongmei.gu@usda.gov (H.G.); richard.d.bergman@usda.gov (R.B.) \\ * Correspondence: nathaniel.m.anderson@usda.gov
}

Citation: Anderson, N.; Gu, H.; Bergman, R. Comparison of Novel Biochars and Steam Activated Carbon from Mixed Conifer Mill Residues. Energies 2021, 14, 8472. https:// doi.org/10.3390/en14248472

Academic Editor: Mejdi Jeguirim

Received: 6 November 2021

Accepted: 10 December 2021

Published: 15 December 2021

Publisher's Note: MDPI stays neutral with regard to jurisdictional claims in published maps and institutional affiliations.

Copyright: (c) 2021 by the authors. Licensee MDPI, Basel, Switzerland. This article is an open access article distributed under the terms and conditions of the Creative Commons Attribution (CC BY) license (https:// creativecommons.org/licenses/by/ $4.0 /)$.

\begin{abstract}
There is increasing demand in environmental remediation and other sectors for specialized sorbents made from renewable materials rather than hard coals and minerals. The proliferation of new pyrolysis technologies to produce bio-based energy, fuels, chemicals, and bioproducts from biomass has left significant gaps in our understanding of how the various carbonaceous materials produced by these systems respond to processes intended to improve their adsorption properties and commercial value. This study used conventional steam activation in an industrial rotary calciner to produce activated carbon (AC) from softwood biochars made by three novel pyrolysis systems. Steam was injected across four heating zones ranging from $816^{\circ} \mathrm{C}$ to $927^{\circ} \mathrm{C}$ during paired trials conducted at calciner retention times of $45 \mathrm{~min}$ and $60 \mathrm{~min}$. The surface area of the three biochars increased from 2.0, 177.3, and $289.1 \mathrm{~m}^{2} \mathrm{~g}^{-1}$ to 868.4, 1092.9, and $744.8 \mathrm{~m}^{2} \mathrm{~g}^{-1}$, respectively. AC iodine number ranged from 951 to $1218 \mathrm{mg} \mathrm{g}^{-1}$, comparing favorably to commercial AC produced from bituminous coal and coconut shell. The results of this study can be used to operationalize steam activation as a post-processing treatment for biochar and to expand markets for biochar as a precursor in the manufacture of specialized industrial sorbents.
\end{abstract}

Keywords: activated carbon; biochar; woody biomass; pyrolysis; steam activation; adsorbent

\section{Introduction}

\subsection{Background}

Biochar is an anthropogenic pyrogenic carbonaceous material used as a soil amendment. It can be made from biomass using a wide range of methods, from wooden ricks, earth mound kilns, and small portable flame-cap kilns to large-scale industrial pyrolysis systems. In all cases, it is the product of the thermal decomposition of biomass in an inert or low oxygen atmosphere, which removes volatile compounds and leaves a high-carbon char. Depending on the circumstances, amending soils with biochar can improve soil properties and plant growth by enhancing nutrient retention, water holding capacity, organic matter content, bulk density, biological activity, and other soil characteristics and processes [1]. Other benefits of biochar, not directly related to improving soils for plant growth, include carbon sequestration and waste management as well as benefits from the renewable energy and fuel products that are coproduced by some pyrolysis systems [2]. Compared to conventional charcoal manufacturing, which is often focused on making solid fuels for combustion, many of the advanced pyrolysis systems that produce biochar are designed to simultaneously meet soil, waste management, climate, and energy objectives [3].

A variety of recent review papers have described biomass feedstocks [4], pyrolysis of biomass $[5,6]$, and biochar production and end use [7,8]. Given the diversity of feedstocks, conversion processes and postprocessing techniques for various end uses, biochar exhibits wide variation in its physical and chemical properties [9]. Table 1 summarizes some of the main characteristics of biochar according to standards established by the International 
Biochar Initiative (IBI, first publication May 2012 [10]) and the European Biochar Certificate (EBC, first publication March 2012 [11]). The establishment of such standards was driven in part to clearly define biochar and to distinguish it from competing products such as low-carbon fly ash and coal-based carbon adsorbents that may have some, but not all of biochar's positive benefits as a soil amendment. Such standards also reduce the possibility that contaminants will be introduced into the soil from biochar amendment, including polycyclic aromatic hydrocarbons (PAHs), polychlorinated biphenyls (PCB), dioxins, and furans, which can form during pyrolysis. Even under these standards, wide variation is common among biochars in properties such as carbon content, ash content, molar $\mathrm{H}$ : $\mathrm{C}$ ratio, macronutrient concentrations, electrical conductivity, $\mathrm{pH}$, bulk density, particle size, water content, surface area, water holding capacity, volatile content, and others. The biochars produced in this study are compared to these standards in Section 3.

Table 1. Thresholds for specific properties set by two widely used biochar standards, the European Biochar Certificate (EBC 2019) Version 8.3E [11] and the International Biochar Initiative (IBI) Biochar Standards Version 2.1 [10].

\begin{tabular}{|c|c|c|}
\hline Criterion & IBI Standard & EBC Standard \\
\hline Feedstock & $\begin{array}{l}\text { Biomass, not including municipal solid waste, } \\
\text { hazardous materials, or hazardous wastes } \\
10 \% \text { minimum in } 3 \text { classes: }\end{array}$ & $\begin{array}{l}\text { Organic substances listed in the standard, free of } \\
\text { contaminants listed in the standard }\end{array}$ \\
\hline Carbon content $\left(\% \mathrm{dw}{ }^{1}\right)$ & $\begin{array}{c}\text { Class } 1: \geq 60 \% \\
\text { Class } 2: \geq 30 \% \text { and }<60 \% \\
\text { Class } 3: \geq 10 \% \text { and }<30 \%\end{array}$ & $\geq 50 \%$ \\
\hline Molar $\mathrm{H}: \mathrm{C}_{\text {organic }}$ ratio & 0.7 maximum & 0.7 maximum \\
\hline Surface area $\left(\mathrm{m}^{2} \mathrm{~g}^{-1}\right)$ & No minimum & No minimum, preferably higher than $150 \mathrm{~m}^{2} \mathrm{~g}^{-1}$ \\
\hline Heavy metals & $\begin{array}{l}\text { Specific maximum levels } \\
\text { set for most metals }\end{array}$ & $\begin{array}{l}\text { Specific maximum levels set for most metals in } \\
\text { two different grades }\end{array}$ \\
\hline $\mathrm{PAHs}^{2}$ & $6-300 \mathrm{mg} \mathrm{kg}^{-1}$ & $\begin{array}{l}\text { Basic grade: }<12 \mathrm{mg} \mathrm{kg}^{-1} \\
\text { Premium grade: }<4 \mathrm{mg} \mathrm{kg}^{-1}\end{array}$ \\
\hline $\mathrm{PCBs}^{3}$ & $0.2-0.5 \mathrm{mg} \mathrm{kg}^{-1}$ & $<0.2 \mathrm{mg} \mathrm{kg}^{-1}$ \\
\hline Dioxins and furans & $<17 \mathrm{ng} \mathrm{kg}^{-1}$ & $<20 \mathrm{ng} \mathrm{kg}^{-1}$ \\
\hline
\end{tabular}

${ }^{1}$ Percent mass on a dry weight basis. ${ }^{2}$ Sum of 16 polycyclic aromatic hydrocarbons identified for testing by the United States Environmental Protection Agency. ${ }^{3}$ Polychlorinated biphenyls.

Biochar can be used in a wide range of soil applications that cut across agriculture, forestry, mining, energy, horticulture, plant nursery, and other sectors. Many of the benefits of biochar application to soils are related to its surface characteristics and adsorbent properties, which can be enhanced through various physical and chemical treatments. Biochar processing following pyrolysis can include screening, grinding, granularization or pelletization, $\mathrm{pH}$ balancing, composting, blending with chemical fertilizers and organics such as manure, inoculation with desirable microbes, and activation by chemical or physical treatments to increase surface area and promote ion exchange [3]. Even without additional processing, biochar can serve as an effective adsorbent and has been the subject of widespread interest and research in applications to reduce runoff, control leaching from mine sites, and filter drinking water [12]. It has also been proven effective as a low-cost adsorbent for the removal of heavy metals and organic contaminants in wastewater $[13,14]$.

By definition, biochar is used in soil. However, there is significant interest in developing biochar-based products for non-soil applications. These include fuel pellets and briquettes, chemicals, feedstocks for gasification, pigments and dyes, construction materials, specialized industrial sorbents, carbon additives in tires, activated carbon (AC), and other carbon products. From an investment and manufacturing standpoint, alternative uses of biochar provide opportunities to diversify product lines and expand into new, complementary markets. They also provide opportunities to substitute renewable bio-based products for petroleum-, coal-, and mineral-based products that have higher greenhouse gas emissions and negative climate impacts. For example, AC from biochar has been shown to have less than half the life cycle greenhouse gas emissions than coal 
derived AC because of lower energy consumption and the biogenic carbon benefit inherent in sustainable woody biomass feedstocks $[15,16]$.

Though process improvements continue to be made, the basic technologies for industrial scale production of AC have been widely known since the early 20th century. As early as 1900, metal chlorides and carbon dioxide at high temperature have been used in the production of commercial AC, with some of the first industrial AC used as a decolorizer in the sugar industry [17]. Soon after, AC from coconut shell (Cocos nucifera) was used in military gas masks in World War I [17]. As Hagemann et al. describe [18], activated carbon, biochar, and charcoal each have distinct but overlapping histories, with somewhat different scientific communities and bodies of literature that can use slightly different terminologies. However, by the 1950s, "activation" was generically understood as a process that improves the adsorptive capacity of a material and more specifically defined as "any process which selectively removes the hydrogen or hydrogen-rich fractions from a carbonaceous raw material in such a manner as to produce and open, porous residue" [19].

Activation of a wide range of carbonaceous precursors from many different feedstocks can be accomplished in a variety of ways at scale to meet the requirements of diverse end uses. Several recent papers have thoroughly reviewed novel uses of AC, the technologies available for activation, and recent advances in this field (e.g., [20-23]), some specifically in relation to biochar [18,24]. A detailed review was beyond the scope of this paper, but several things are worth mentioning here as a primer. Activated carbon is used in a wide variety of products in different sectors, with the largest markets being water treatment, air and emissions treatment, respirators, metallurgical applications such as the beneficiation of gold ore, and industrial uses to recover solvents and process chemicals. AC is also used in the medical and pharmaceutical sectors, especially to purify drugs.

Activation techniques fall into two basic categories: physical and chemical. Physical activation includes treatment with steam, carbon dioxide, nitrogen, argon, or another inert gas at relatively high temperatures $\left(>800^{\circ} \mathrm{C}\right)$. In most cases, wood or other biomass feedstocks are carbonized by pyrolysis in an inert or low oxygen environment prior to physical activation, as described previously. During physical activation with steam, water vapor reacts with carbon in an oxidation reaction to produce $\mathrm{CO}$ and $\mathrm{H}_{2}$. Carbon in the precursor is consumed, and pores open and deepen as a function of time and the intensity of oxidation, which increases the porosity and surface area of the material. Chemical activation can occur at lower temperatures $\left(>500^{\circ} \mathrm{C}\right)$ and involves chemical impregnation of the feedstock or precursor with $\mathrm{H}_{3} \mathrm{PO}_{4}, \mathrm{ZnCl}_{2}, \mathrm{KOH}$, or some other dehydrating chemical agent. Carbonization and activation can be conducted simultaneously or separately, with impregnation occurring before or after carbonization.

Currently, most commercial AC is made from coal (i.e., activated coal), wood, coconut shell, or nutshell. Among the biomass feedstocks, the use of pine softwood (Pinus spp.) and herbaceous biomass is less common because these are generally perceived as resulting in AC with less favorable adsorption properties, material handling (e.g., hardness and friability), and regenerative capacity compared to coconut shell and hardwood (e.g., Betula spp., Carpinus spp.). For example, Tseng et al. [25] reported steam activated pinewood AC having a surface area of 426 and $902 \mathrm{~m}^{2} \mathrm{~g}^{-1}$, compared to steam activated teak (Tectona grandis) AC with a surface area of $1150 \mathrm{~m}^{2} \mathrm{~g}^{-1}$ [26]. However, pine sawdust has been successfully activated to surface areas higher than $1800 \mathrm{~m}^{2} \mathrm{~g}^{-1}$ using $\mathrm{ZnCl}_{2}$ [27]. Danish and Ahmad [28] provide a comprehensive review of the utilization of wood biomass as a sustainable feedstock for activated carbon that shows high variability in AC properties across different feedstocks and processes. This emphasizes the need for targeted and integrated research on specific feedstocks, carbonization processes, activation methods, and end uses. 


\subsection{Rationale}

Carbonized wood is already widely used in the manufacture of industrial sorbents and the techniques to produce AC from wood using steam are generally well understood and have been deployed industrially at scale for over a century. However, a wide range of new pyrolysis technologies are being developed and deployed for biochar production, waste management, energy and fuel production, and carbon capture for climate change mitigation. Some advanced pyrolysis systems are designed to accomplish all of these objectives simultaneously. The variability in their design, size, performance, and products makes targeted research critical in the development of useful adsorbents from the carbonaceous products of these systems. Furthermore, because their deployment is often related to waste management of forest and agricultural biomass residues that are not conventionally used in the manufacture of $\mathrm{AC}$, it is important to understand how AC made from these feedstocks processed by new pyrolysis technologies are likely to perform as precursors when subjected to conventional activation methods. In this context, uncertainty in the characteristics and performance of $\mathrm{AC}$ from these systems and their feedstocks can be a barrier to investment, especially if the intent is to manufacture renewable substitutes for products that are already widely used.

To directly address this need, this study produced AC from the biochar products of three different novel industrial pyrolysis systems using softwood mill residue feedstocks. The objectives were to demonstrate how the biochars produced by these systems respond to steam activation, quantify the performance properties of resultant $\mathrm{AC}$, and compare the resultant AC to those of two commercially available products. The goal is to facilitate the deployment of pyrolysis systems and the manufacture of renewable bio-based products by reducing the uncertainty associated with steam activation as a technique to enhance biochar for soil amendment and manufacture commercial AC from biochar. The research presented here was conducted as a component of a larger integrated evaluation of forest biomass feedstock production, logistics, conversion, distribution, and end use focused on novel pyrolysis technologies deployed in the forest sector [29].

\section{Materials and Methods}

\subsection{Feedstock}

All three biochars used in this study were produced from wood chips generated from debarked mill wood residues including whole logs, edge slabs, log ends, and other materials. Though it was not possible to determine the exact species composition of the feedstocks because they were collected from active mill operations processing multiple species at the same time, in all cases, the feedstock was predominantly Pinus ponderosa or Pinus contorta, with minor components of other coniferous species. Table 2 shows the chemical composition of two samples of these feedstocks collected at a sawmill in Colorado, USA. Debarked mill residues were chipped to between $13 \mathrm{~mm}$ and $76 \mathrm{~mm}$ ( 0.5 and 3.0 inches) in the longest dimension prior to pyrolysis, depending on system requirements. Additional feedstock processing prior to pyrolysis including supplemental drying are described below for specific pyrolysis systems. Additional information on the chemical and physical properties of coniferous woody biomass feedstocks can be found in [28] and in the Bioenergy Feedstock Library maintained by the Idaho National Laboratory [30].

\subsection{Pyrolysis}

Biochar precursors were produced using three different systems operated by three different companies: Biochar Solutions Incorporated (BSI; Carbondale, CO, USA); Tucker Engineering Associates (TEA; Locust, NC, USA); and Confluence Energy (CON; Kremmling, CO, USA). Table 3 characterizes these systems with regard to throughput, reactor type, feedstock, temperature, retention time, and the use of supplemental gas during pyrolysis. Figure 1 shows process diagrams for the three systems including the activation process, which was conducted in a different location than pyrolysis. 
Table 2. Chemical composition of debarked Pinus ponderosa and Pinus contorta mill residues.

\begin{tabular}{ccc}
\hline & Sample \\
Variable & $\begin{array}{c}\text { Mill Residues } \\
\text { Pinus ponderosa }\end{array}$ & $\begin{array}{c}\text { Mill Residues } \\
\text { Pinus contorta }\end{array}$ \\
\hline Volatile carbon $\left(\% \mathrm{dw}^{1}\right)$ & 37.24 & 38.92 \\
Fixed carbon $(\% \mathrm{dw})$ & 12.80 & 12.25 \\
Total carbon $(\% \mathrm{dw})$ & 50.04 & 51.17 \\
Fixed C:Total C (\%) & 25.58 & 23.94 \\
Oxygen (\% dw) & 41.03 & 41.16 \\
Hydrogen $(\% \mathrm{dw})$ & 5.94 & 6.17 \\
Nitrogen $(\% \mathrm{dw})$ & 0.11 & 0.13 \\
Sulfur $(\% \mathrm{dw})$ & 0.02 & 0.03 \\
Ash $(\% \mathrm{dw})$ & 2.86 & 1.34 \\
\hline
\end{tabular}

${ }^{1}$ Percent mass by dry weight.

Table 3. Basic characteristics of the three pyrolysis systems used in this study.

\begin{tabular}{|c|c|c|c|}
\hline Variable & $\begin{array}{l}\text { Biochar Solutions Inc. } \\
\text { (BSI) }\end{array}$ & $\begin{array}{c}\text { Tucker Engineering Associates } \\
\text { (TEA) }\end{array}$ & Confluence Energy (CON) \\
\hline Throughput & Continuous & Continuous & Continuous \\
\hline Reactor type & $\begin{array}{l}\text { Two stage pyrolysis, } \\
\text { two vertical reactors }\end{array}$ & $\begin{array}{l}\text { Gasifier, auger system with } \\
\text { char output }\end{array}$ & $\begin{array}{c}\text { Gasifier, with integrated } \\
\text { pyrolysis tube }\end{array}$ \\
\hline Feedstock & Pinus ponderosa ${ }^{1}$ & Pinus contorta ${ }^{2}$ & Pinus contorta ${ }^{2}$ \\
\hline Temperature & $\begin{array}{l}700 \text { to } 7500^{\circ} \mathrm{C} \\
\text { then } 400^{\circ} \mathrm{C} \text { to } 5500^{\circ} \mathrm{C}\end{array}$ & $870^{\circ} \mathrm{C}$ & $1000^{\circ} \mathrm{C}$ \\
\hline Retention time & $\begin{array}{l}\text { Stage } 1:<1 \mathrm{~min} \\
\text { Stage } 2: 15 \mathrm{~min}\end{array}$ & $3 \mathrm{~min}$ & $45 \mathrm{~min}$ \\
\hline Supplemental gas & None & None & None \\
\hline Oxygen & $\begin{array}{c}\text { Some oxidative } \\
\text { combustion in stage } 1\end{array}$ & $\begin{array}{c}\text { Limited air in interparticle space } \\
\text { in feedstock }\end{array}$ & $\begin{array}{c}\text { Limited air in interparticle space } \\
\text { in feedstock }\end{array}$ \\
\hline
\end{tabular}

${ }^{1}$ Mixed conifer feedstock, predominantly Pinus ponderosa. ${ }^{2}$ Mixed conifer feedstock, predominantly Pinus contorta.

BSI biochar was produced using a modular pyrolysis reactor processing debarked, chipped Pinus ponderosa edge slabs, and log ends from a sawmill. Chips were screened to less than $76 \mathrm{~mm}$ in the longest dimension. As described in Kim et al. [31], carbonization occurred in an exothermic reaction at temperatures between $400{ }^{\circ} \mathrm{C}$ and $750{ }^{\circ} \mathrm{C}$. Biochar is the primary output of this system, with process heat and relatively low energy gas as coproducts [32]. This system uses a two-stage reactor. In the first stage, feedstock is heated in a controlled aerobic environment with limited oxygen at a temperature between $700{ }^{\circ} \mathrm{C}$ and $750{ }^{\circ} \mathrm{C}$ for less than $1 \mathrm{~min}$. An oxidative combustion reaction, typically using propane as a fuel source, is required to start the BSI reactor, but once the reaction is started, no additional external heat is required to maintain it. The material then passes into a separate second reactor, where it is held in a sweep gas environment for approximately 10 to $15 \mathrm{~min}$ at a temperature between $400{ }^{\circ} \mathrm{C}$ and $550{ }^{\circ} \mathrm{C}$, depending on its position in the reactor. Supplemental gas was not used in this system. The biochar is removed from the second reactor by a liquid cooled auger with an air lock, which results in dry biochar output. The gas produced during the first stage of pyrolysis is pulled through the system by a blower, acting as the sweep gas for the second stage. Though some limited oxidation occurs in the first stage, oxidation is very low in the second stage because the sweep gas is composed primarily of carbon monoxide, nitrogen, methane, and hydrogen generated by the pyrolysis reaction. BSI biochar was not screened prior to activation. 
(a)

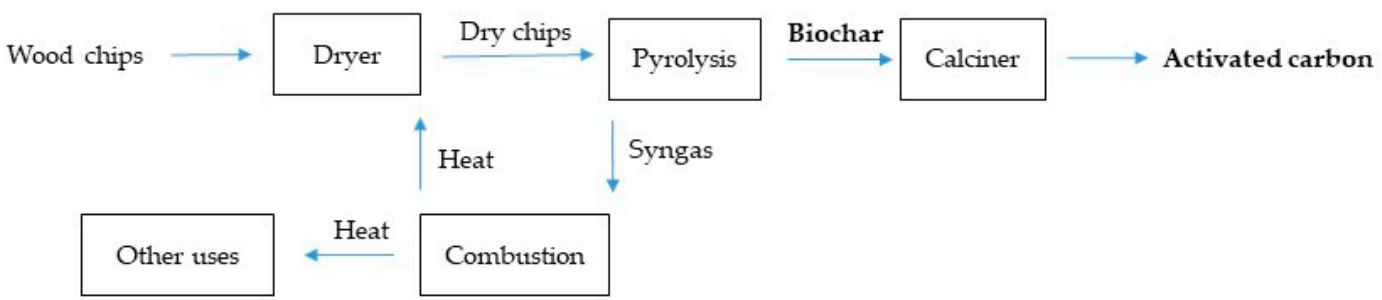

(b)

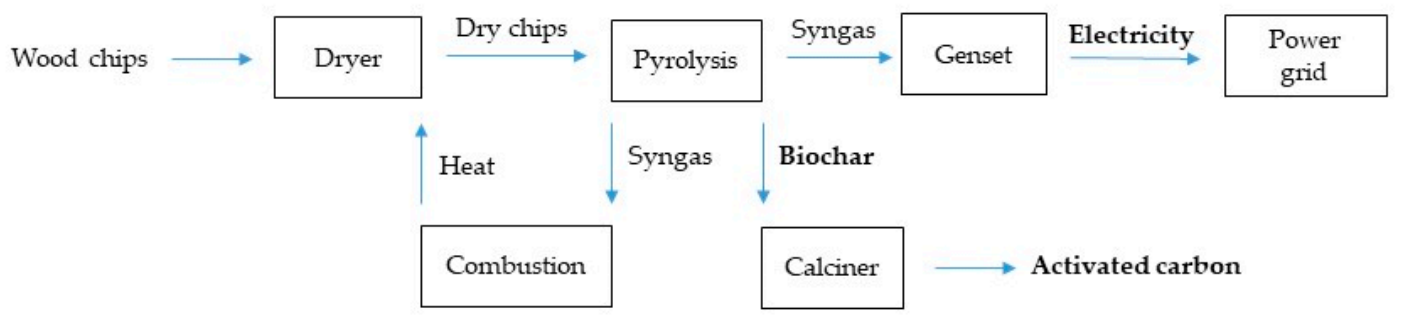

(c)

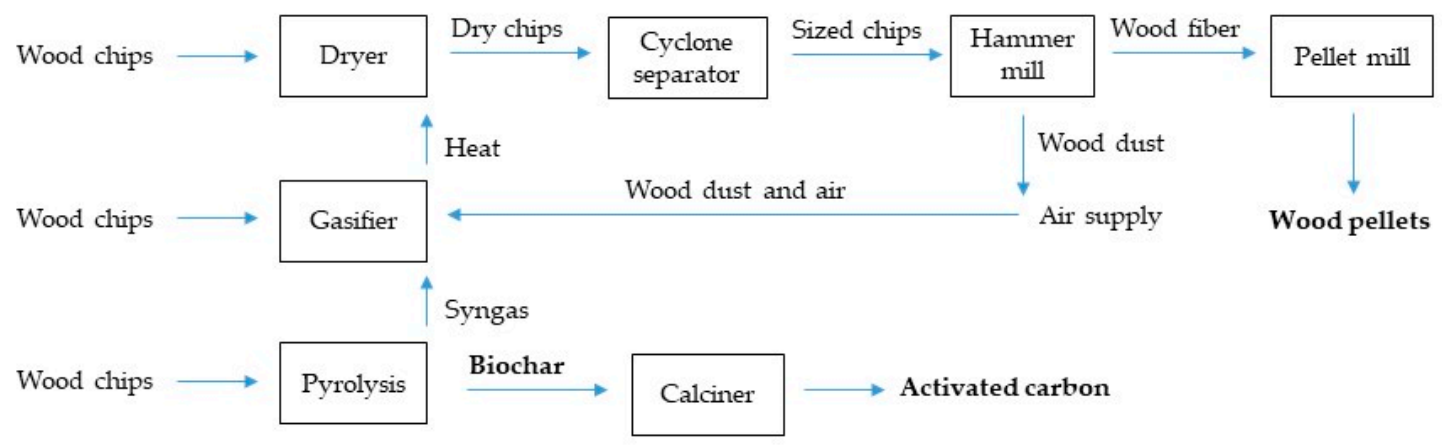

Figure 1. Process diagrams for the pyrolysis systems included in this study: (a) Biochar Solutions Incorporated (BSI), (b) Tucker Engineering Associates (TEA), and (c) Confluence Energy (CON). Primary outputs of these systems are indicated in bold type. Activation in a rotary calciner was conducted in a different location than pyrolysis using the same calciner for all three biochars. TEA $(\mathbf{b})$ includes a syngas compression and storage process between pyrolysis and the genset.

In contrast to the BSI system, the primary product of the TEA pyrolysis system is high quality synthesis gas (i.e., syngas) for energy and chemical applications with biochar as a coproduct. The auger-based system was designed to produce syngas with a high methane content from a wide range of feedstocks including coal, municipal solid waste, biomass, and others. Biochar was also a consideration in the design of the system, with a focus on engineering continuous output of biochar suitable for activation. In this case, feedstock was produced from Pinus contorta harvested from forests in Montana and Idaho, USA. Non-sawlog roundwood was sorted, debarked, chipped, and screened into micro-chips less than $13 \mathrm{~mm}$ in the longest dimension, and then dried to less than $10 \%$ moisture content prior to pyrolysis.

The details of the TEA conversion process can be found in $\mathrm{Gu}$ and Bergman $[33,34]$. Carbonization occurred in an endothermic reaction at a temperature of $870{ }^{\circ} \mathrm{C}$ with a retention time of $3 \mathrm{~min}$, followed by a water quench to cool the biochar, reduce dust pollution, and improve material handling. In addition to providing process heat, syngas produced by the TEA system fueled a 1 MW genset (i.e., internal combination engine and alternator) to produce renewable power for the electric grid. The composition of TEA syngas from softwood chips has been measured as $48 \%$ carbon monoxide, $17 \%$ hydrogen, $15 \%$ methane, $11 \%$ carbon dioxide, and $3.7 \%$ ethylene by volume, with very low oxygen and nitrogen content [33]. Unlike gasifiers that inject oxygen, steam, or air to achieve 
optimal oxidation for syngas production, the TEA system restricts oxidation to the extent possible with a double air lock and a positive pressure sweep gas environment. Though the main reactor can accept supplemental process gas such as nitrogen, no additional gas was used in the production of the biochar used in this study. Some oxidation does occur as a function of air in the interparticle space of the feedstock, which cannot be fully evacuated. TEA biochar was not screened prior to activation. No screening was needed due to the relatively intensive feedstock processing that occurred at the mill, which translated into suitable feedstock for pyrolysis and a relatively uniform biochar product for activation.

CON biochar was produced at a wood pellet mill. A typical pellet mill has a significant heat demand for drying the wood used in pellets [35]. Confluence Energy used a gasification system to meet $1 \mathrm{MW}$ of process heat demand. Heat is produced by combusting the syngas generated when sawdust is blown into the gasifier and heated at high temperature with controlled air flow and low oxidation. A pyrolytic tube was integrated into the CON gasification system to provide both additional gas to the gasifier and to produce biochar that was sold in its raw form and also used in manufactured sorbent products such as pet litter and wattles to control sedimentation and contamination from surface runoff. The auger-based system allowed for the control of retention time between 45 and 75 min, with a maximum outside temp on the surface of the tube within the gasifier of $1260{ }^{\circ} \mathrm{C}$. Like the TEA system, some minimal oxidation does occur as a function of air trapped in the interparticle space of the feedstock, which cannot be fully evacuated with an airlock alone, but oxidation is low. For more information about the operation of this system, see [35]. For this study, pre-dried Pinus contorta wood chips were processed in an endothermic reaction at $1000{ }^{\circ} \mathrm{C}$ with a retention time of $45 \mathrm{~min}$. Biochar was then screened after cooling to remove particles less than $6 \mathrm{~mm}$ prior to activation.

\subsection{Activation}

All three biochars were activated with super-heated steam in a nitrogen-purged rotary electric calciner used for pilot-scale process testing and equipment engineering (Figure 2; Raymond Bartlett-Snow LLC, ARVOS Group, Warrenville, IL, USA). Steam was heated to $550{ }^{\circ} \mathrm{C}$ in an electric circulation purge heater prior to entering a steam lance at the calciner feed end. The steam was further heated as it traveled through the lance pipe inside the calciner prior to its injection into the cylinder, which was operated with four temperature zones, with the first set at $816^{\circ} \mathrm{C}$ and the next three set at $927{ }^{\circ} \mathrm{C}$. This temperature range was determined to be optimal for wood biochar based on ARVOS expert opinion and previous trials on the same equipment [32]. Steam was injected at a ratio of $1.5 \mathrm{~kg}$ for every $1 \mathrm{~kg}$ of biochar. Nitrogen was injected at a rate of 2.89 standard $\left(20{ }^{\circ} \mathrm{C}\right.$ at $101.325 \mathrm{kPa}) \mathrm{m}^{3} \mathrm{~s}^{-1}$.

None of the biochars received additional processing or preparation prior to activationThey were placed in a hopper as received from the manufacturers and introduced into the cylinder from the hopper through a nitrogen purged feed system. Cylinder rotation speed and biochar feed rate were adjusted to achieve retention times of 45 and 60 min in separate trials. The calciner was fully evacuated between trials. Six independent trials were conducted over three days to activate each of the three biochars at both retention times. Before activation, bulk density of the biochars from the BSI, TEA, and CON systems were 192,228 , and $192 \mathrm{~kg} \mathrm{~m}^{-3}$, respectively.

The material and energy inputs for the calciner were estimated as $33.6 \mathrm{~kg}$ biochar per hour, with natural gas and electricity inputs estimated at $36.96 \mathrm{~m}^{3} \mathrm{~h}^{-1}$ and $27 \mathrm{~kW}$, respectively [15]. During steam activation, carbon in the precursor is consumed. A measurement of mass loss from burn-off and material loss in the system was calculated based on the difference between the input biochar and output AC for each run. Mass loss during the trials averaged 57.3\% loss, but additional experiments would be needed to develop an accurate model of burn-off mass loss as a function of retention time. Previous research has reported mass and energy balances for the TEA and BSI systems. Bergman and Gu [33] calculated net energy gain of the TEA system without activation as $2019.8 \mathrm{MJ} \mathrm{h}^{-1}$ and 
8.6 $\mathrm{MJ} \mathrm{kg}^{-1}$ feedstock (per oven dry kg) by mass for the system running $263 \mathrm{~kg} \mathrm{~h}^{-1}$ at $12 \%$ feedstock moisture content. Sahoo et al. [36] reported the BSI system consuming $500 \mathrm{~kg} \mathrm{~h}^{-1}$ of softwood chips at $36 \%$ moisture content to produce $75 \mathrm{~kg} \mathrm{~h}^{-1}$ of biochar at $2 \%$ moisture content, with an electricity demand of $20.5 \mathrm{~kW}$ and surplus process heat of $6534 \mathrm{MJ} \mathrm{h}^{-1}$. Similar studies have not yet been conducted for the CON system.

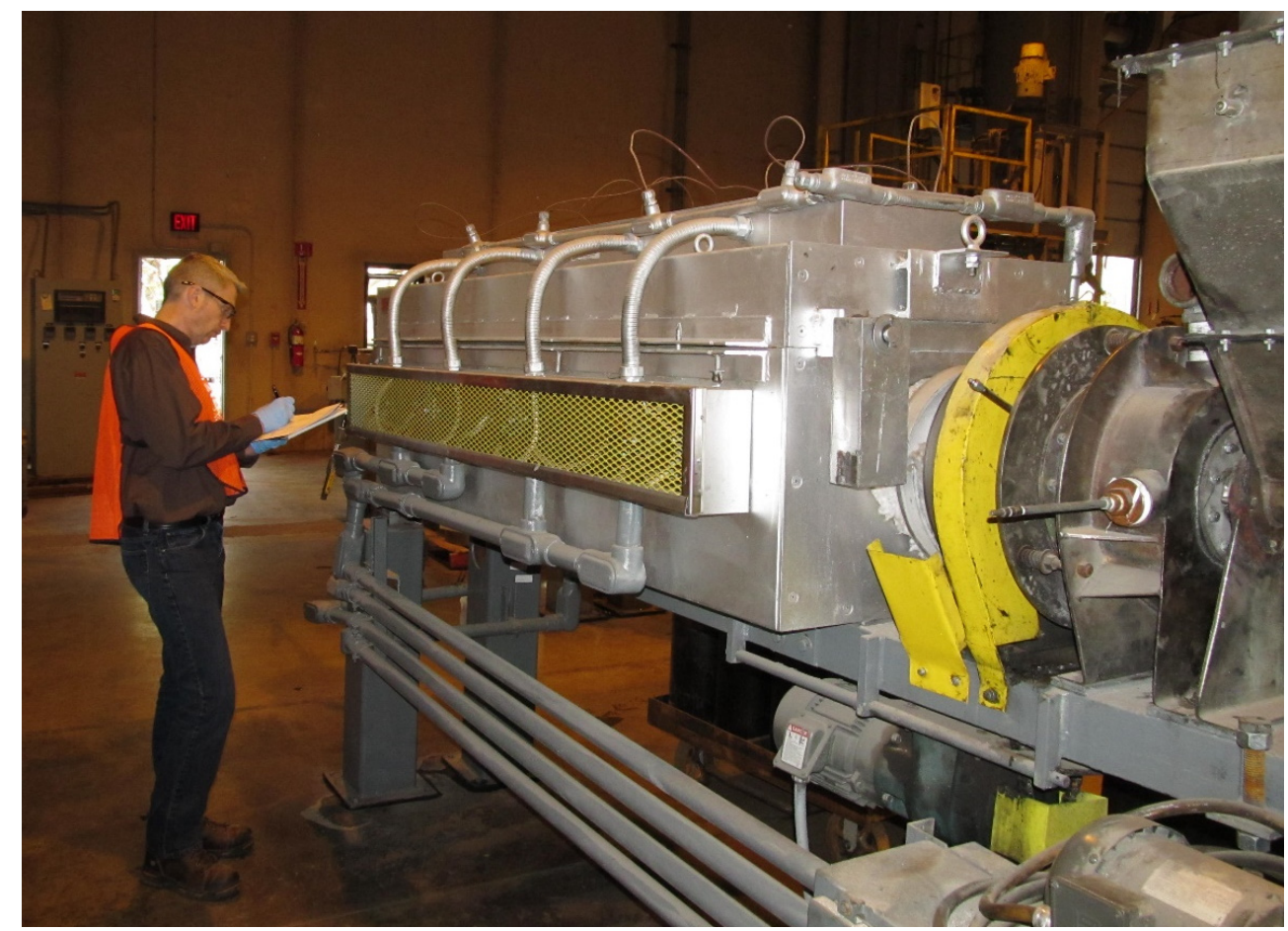

Figure 2. The calciner used in this study shown with one of the authors for scale. Biochar was fed from the hopper on the right into the inlet of the calciner and then moved down the rotating tube from right to left, moving through four heating zones. Photo credit: N. Anderson.

\subsection{Analysis}

Three biochar precursors and their six resultant AC (three at 45 min retention time and three at $60 \mathrm{~min}$ retention time) were characterized by their chemical composition, adsorption properties (e.g., isotherms, pore size distributions, surface area, and iodine number) and scanning electron microscopy (SEM). All samples were analyzed using the same methods by the same independent laboratory staff at the same time for each set of tests.

Proximate and ultimate analyses were conducted according to American Society for Testing and Materials (ASTM) standards. Proximate analysis for moisture, volatile matter, carbon, and ash was conducted using thermogravimetric analysis following ASTM D758212. Ultimate analysis for moisture, ash, sulfur, carbon, hydrogen, nitrogen, and oxygen were conducted using ASTM E870-82. The determination of total carbon and total nitrogen for both the feedstocks and biochars were made by dry combustion on a TruSpec CN analyzer (LECO Corporation, St. Joseph, MI, USA), which uses an infrared detector to measure carbon and a thermal conductivity cell to determine nitrogen. Samples were dried and homogenized prior to analysis and feedstocks were ground to pass through a $420 \mu \mathrm{m}$ screen. Biochar and $\mathrm{AC}$ were ground into a fine powder. Higher oxygen flow during the burn phase was used for these materials to ensure complete combustion of the material. Energy content was determined by calorimetry using a Parr bomb calorimeter calibrated with a standard of benzoic acid.

Elemental analysis including heavy metals was carried out using a Horiba (Edison, NJ, USA) Ultima II high resolution spectrometer for inductively coupled plasma-optical 
emission spectrometry (ICP-OES). Acquisition was conducted using three replicates in max mode and a $1 \mathrm{~s}$ integration time for each analyte. Samples were analyzed in multiple runs, depending on the anticipated concentration of a group of analytes: 0-5 ppm, 0-20 ppm, and $0-100$ ppm. Sample solutions $>100$ ppm were diluted 1 to 10 , then re-analyzed after re-calibration.

Brunauer-Emmet-Teller (BET) surface area was measured by nitrogen gas sorption analysis at $77 \mathrm{~K}$ using a BET-201-APC Sorptometer (Porous Materials Incorporated, Ithaca, NY, USA). Before analysis, $1.0 \mathrm{~g}$ samples were vacuum outgassed to $20 \mu \mathrm{m}$ at $20{ }^{\circ} \mathrm{C}$, with variable outgassing time. Sorption analysis was also used to calculate total pore volume, porosity, and several measures of pore diameter. Iodine number is a measure of adsorption

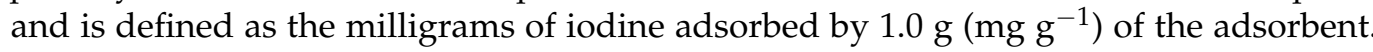
Iodine number was calculated by titration at $30{ }^{\circ} \mathrm{C}$ according to the ASTM D4607-94 standard. Iodine number was used here as a practical measure of the relative porosity and adsorptive capacity of the samples because it is a simple and inexpensive metric used by industry to characterize adsorbents.

SEM imagery was taken on a JEOL NeoScope II (JEOL USA, Inc., Peabody, MA, USA) with a secondary electron detector at magnifications of $40 \times, 200 \times, 1000 \times, 5000 \times, 5500 \times$, and $8000 \times$. The samples were prepared by mounting each sample to a stub using carbon tape, followed by gold sputtering.

\subsection{Reference Samples}

The literature provides information on the properties of AC produced in the laboratory from a wide range of biomass materials using many different carbonization and activation methods. With some notable exceptions, e.g., [12], it is not always clear how such materials might measure up to commercial products available in the marketplace, especially if the properties reported by commercial sellers are not independently validated. For reference, the properties of the AC produced in this study are compared to those of two commercially available activated carbon products: one made from coconut shell and one made from bituminous coal. Both commercial products are marketed for consumer water filtering applications and were purchased online. According to the manufacturers, both were made using high temperature steam activation, but the details of their processes are considered proprietary. With information on the conditions of their manufacture, it would be possible to relate the adsorption properties of these products to conditions of their production. However, the necessary proprietary process data were not made available to the authors for this purpose. To facilitate equivalent comparison of their properties and performance, samples of both commercial AC products were analyzed concurrently by the same personnel using the exact same methods as the biochars and AC produced in this study.

\section{Results}

\subsection{Chemical Composition}

All three biochars met the standards for biochar chemical characteristics as determined by IBI and EBC [10,11]. With total carbon content of $86.42 \%, 86.96 \%$, and $93.47 \%$ for BSI, TEA, and CON biochars, respectively, they met the carbon content standard of $\geq 60 \% \mathrm{dw}$ for Class 1 biochar under the IBI standard (Tables 1 and 4). Ash content ranged from 2.86 to $6.73 \% \mathrm{dw}$, which is typical for biochars from wood feedstocks [28,37]. The molar H:C $\mathrm{C}_{\text {organic }}$ ratio serves as a benchmark for the stability of the carbon in the biochar, with thermally altered biomass showing a lower ratio than its parent biomass [10]. These biochars were produced at relatively high temperatures and all showed low $\mathrm{H}: \mathrm{C}_{\text {organic }}$ ratios as a result, indicating higher incidents of fused aromatic rings and other stable molecular structures. Heating values are included in Table 4 because biochar has been studied as a solid fuel substitute for coal and its fuel value has been used as a benchmark for its minimum market price in technoeconomic analysis [38]. Higher heating value for these biochars was similar 
to that of bituminous coal, and about twice the higher heating value of woody biomass residues from forest management [39].

Table 4. Chemical characteristics and heating value of the three biochars and their associated activated carbon (AC) produced at two different calciner retention times of $45 \mathrm{~min}$ and $60 \mathrm{~min}$.

\begin{tabular}{|c|c|c|c|c|c|c|c|c|c|}
\hline \multirow{3}{*}{$\begin{array}{c}\text { Variable } \\
\text { Sample Type }\end{array}$} & \multicolumn{9}{|c|}{ Sample ${ }^{1}$} \\
\hline & \multicolumn{3}{|c|}{ BSI } & \multicolumn{3}{|c|}{ TEA } & \multicolumn{3}{|c|}{$\mathrm{CON}$} \\
\hline & Biochar & AC & $\mathrm{AC}$ & Biochar & AC & AC & Biochar & $\mathrm{AC}$ & AC \\
\hline Calciner Time (min) & $\mathbf{0}$ & 45 & 60 & 0 & 45 & 60 & 0 & 45 & 60 \\
\hline Volatile carbon $\left(\% \mathrm{dw}^{2}\right)$ & 13.05 & 8.52 & 3.36 & 8.68 & 2.55 & 2.06 & 3.71 & 1.18 & 8.91 \\
\hline Fixed carbon $(\% \mathrm{dw})$ & 73.37 & 82.43 & 85.55 & 78.28 & 80.24 & 89.75 & 89.76 & 91.69 & 84.72 \\
\hline Total carbon $(\% \mathrm{dw})$ & 86.42 & 90.95 & 88.91 & 86.96 & 82.79 & 91.81 & 93.47 & 92.87 & 93.63 \\
\hline Fixed C:Total C ratio (\%) & 84.9 & 90.6 & 96.2 & 90.0 & 97.0 & 97.8 & 96.0 & 98.7 & 90.5 \\
\hline Oxygen $(\% d w)$ & 5.75 & 1.89 & 6.21 & 6.02 & 2.64 & 2.19 & 2.61 & 2.54 & 0.90 \\
\hline Hydrogen (\% dw) & 0.91 & 0.32 & 0.40 & 2.60 & 0.48 & 0.46 & 0.96 & 0.44 & 0.48 \\
\hline Molar $\mathrm{H}: \mathrm{C}_{\text {organic }}$ ratio & 0.12 & 0.04 & 0.05 & 0.36 & 0.07 & 0.06 & 0.12 & 0.06 & 0.06 \\
\hline Nitrogen $(\% \mathrm{dw})$ & 0.18 & 0.37 & 0.32 & 0.12 & 0.17 & 0.26 & 0.09 & 0.32 & 0.33 \\
\hline Sulfur (\% dw) & 0.01 & 0.01 & $<0.01$ & $<0.01$ & 0.01 & 0.01 & 0.01 & 0.01 & $<0.01$ \\
\hline Ash $(\% \mathrm{dw})$ & 6.73 & 6.46 & 4.16 & 4.30 & 13.91 & 5.27 & 2.86 & 3.82 & 4.66 \\
\hline $\mathrm{HHV}\left(\mathrm{MJ} \mathrm{kg}^{-1}\right)^{3}$ & 29.81 & 30.51 & 30.01 & 31.13 & 27.73 & 30.53 & 31.81 & 31.13 & 31.03 \\
\hline $\mathrm{LHV}\left(\mathrm{MJ} \mathrm{kg}^{-1}\right)^{3}$ & 29.61 & 30.44 & 29.92 & 30.57 & 27.58 & 30.43 & 31.60 & 3104 & null ${ }^{4}$ \\
\hline
\end{tabular}

${ }^{1}$ Sample abbreviations for biochar produced by Biochar Solutions Incorporated (BSI), Tucker Engineering Associates (TEA), and Confluence Energy (CON). ${ }^{2}$ Percent mass on a dry weight basis. ${ }^{3}$ Higher heating value (HHV) and lower heating value (LHV) accounting for moisture content. ${ }^{4}$ The sample was not processed appropriately to allow for this calculation.

All six AC produced also met the biochar standards set by IBI and EBC [10,11], meaning they could be used as soil amendments under these standards. As expected, the AC had similar chemical composition to their precursor biochars, with some minor differences. Except for the CON AC at 60 min retention time, fixed carbon is a higher fraction of the total carbon in the AC compared to their precursor biochars (Table 4) due to additional volatilization of the volatile carbon fraction during the activation process (Table 4). In all cases, the hydrogen content was reduced by activation and the molar $\mathrm{H}: \mathrm{C}_{\text {organic }}$ ratio dropped, indicating further movement toward stable carbon structures in the AC's molecular chain. Heating value was relatively consistent before and after activation.

These biochars and their resultant $\mathrm{AC}$ met the standards for maximum heavy metal concentrations associated with the premium biochar standard under EBC (Table 5). Except for some unusual cases, wood mill residues generally have low incidence of heavy metals because they come from natural wood processed from harvested logs, rather than from post-consumer demolition wood or wood separated from municipal solid waste streams that can have metal contamination from paint, wood preservatives, galvanized screws and nails, plastics, and other sources [40]. In general, except for a few heavy metals that are volatile at pyrolysis temperatures, the heavy metals contained in the feedstock will remain in the biochar and resultant AC [11]. Most heavy metal concentrations are below the maximum thresholds for premium grade (Table 5). At $80 \mathrm{mg} \mathrm{kg}^{-1} \mathrm{Cr}$, CON biochar derived $\mathrm{AC}$ at the $45 \mathrm{~min}$ retention time was at the maximum threshold for chromium for premium grade, but below the $90 \mathrm{mg} \mathrm{kg}^{-1} \mathrm{Cr}$ threshold for basic grade. Concentrations of additional elements including alkali metals $\mathrm{Na}$ and $\mathrm{K}$ are included in Table 6. 
Table 5. European Biochar Certificate (EBC) Version 8.3E maximum values $\left(\mathrm{mg} \mathrm{kg}^{-1}\right)$ for heavy metals at the basic and premium grade levels and concentrations for those metals $\left(\mathrm{mg} \mathrm{kg}^{-1}\right)$ measured in the three biochar precursors and their 45 and 60 min AC products.

\begin{tabular}{|c|c|c|c|c|c|c|c|}
\hline \multirow[b]{2}{*}{ Sample ${ }^{1}$} & \multicolumn{7}{|c|}{ Heavy Metal Concentration (mg kg ${ }^{-1}$ ) } \\
\hline & As & $\mathrm{Cd}$ & $\mathbf{P b}$ & $\mathrm{Cu}$ & $\mathbf{N i}$ & $\mathrm{Zn}$ & $\mathrm{Cr}$ \\
\hline EBC threshold, basic & 13 & 1.5 & 150 & 100 & 50 & 400 & 90 \\
\hline EBC threshold, prem. & 13 & 1.0 & 120 & 100 & 30 & 400 & 80 \\
\hline BSI biochar & nd $^{2}$ & nd & nd & $\leq 10$ & nd & $\leq 10$ & $\leq 10$ \\
\hline BSI AC, $45 \mathrm{~min}$ & nd & nd & nd & $\leq 10$ & nd & $\overline{\text { nd }}$ & $\leq 10$ \\
\hline BSI AC, $60 \mathrm{~min}$ & nd & nd & nd & nd & nd & nd & $\leq 10$ \\
\hline TEA biochar & 2 & nd & nd & $\leq 5$ & 20 & 20 & 30 \\
\hline TEA AC, $45 \mathrm{~min}$ & 4 & nd & nd & $\leq 10$ & 20 & nd & 20 \\
\hline TEA AC, $60 \mathrm{~min}$ & nd & nd & nd & $\leq 5$ & 20 & nd & 25 \\
\hline CON biochar & nd & nd & nd & $\leq 5$ & $\leq 5$ & 10 & $\leq 10$ \\
\hline $\mathrm{CON} A C, 45 \mathrm{~min}$ & $\leq 10$ & nd & $\leq 2$ & $\overline{5} 0$ & $\overline{20}$ & $\leq 30$ & 80 \\
\hline $\mathrm{CON} A C, 60 \mathrm{~min}$ & \multicolumn{7}{|c|}{ no results, sample lost during digestion } \\
\hline
\end{tabular}

${ }^{1}$ Sample abbreviations: European Biochar Certificate (EBC), Biochar Solutions Incorporated (BSI), Tucker Engineering Associates (TEA), and Confluence Energy (CON). ${ }^{2}$ nd: not detectable.

Table 6. Concentrations ( $\mathrm{mg} \mathrm{kg}^{-1}$ ) of selected alkali metals and other elements measured in the three biochar precursors and their 45 and 60 min AC products. Cd, Se, V, and Ag were not detectable for all samples. Concentrations of Co were not detectable or were $\leq 2 \mathrm{mg} \mathrm{kg}^{-1}$ for all samples. The concentration of $\mathrm{B}$ was $\leq 20 \mathrm{mg} \mathrm{kg}^{-1}$ for all samples.

\begin{tabular}{|c|c|c|c|c|c|c|c|c|c|c|c|c|}
\hline \multirow[b]{2}{*}{ Sample $^{1}$} & \multicolumn{12}{|c|}{ Concentration (mg kg $\left.{ }^{-1}\right)$} \\
\hline & $\mathrm{Na}$ & $\mathbf{K}$ & Mg & Mo & Sr & Ba & Mn & $\mathbf{P}$ & $S$ & Al & $\mathrm{Ca}$ & $\mathbf{F e}$ \\
\hline BSI biochar & 200 & 3000 & 2000 & $<1$ & 40 & 40 & 200 & 300 & 150 & 600 & 8000 & 600 \\
\hline $\mathrm{BSI} \mathrm{AC}, 45 \mathrm{~min}$ & 100 & 4900 & 2900 & 80 & 60 & 80 & 500 & 500 & 250 & 400 & 10,000 & 500 \\
\hline $\mathrm{BSI} \mathrm{AC}, 60 \mathrm{~min}$ & 200 & 5000 & 3100 & 10 & 70 & 70 & 300 & 300 & 200 & 600 & 14,000 & 750 \\
\hline TEA biochar & 50 & 1100 & 500 & 1 & 10 & 40 & 150 & 200 & 80 & 300 & 2000 & 1200 \\
\hline TEA AC, $45 \mathrm{~min}$ & 100 & 3800 & 1600 & 100 & 40 & 100 & 600 & 600 & 200 & 350 & 8000 & 2000 \\
\hline TEA AC, $60 \mathrm{~min}$ & 100 & 3900 & 1800 & 20 & 40 & 100 & 600 & 500 & 200 & 400 & 8000 & 1200 \\
\hline CON biochar & 100 & 2400 & 1100 & $<1$ & 30 & 40 & 400 & 150 & 50 & 170 & 5000 & 200 \\
\hline $\mathrm{CON} A C, 45 \mathrm{~min}$ & 100 & 4000 & 1700 & 10 & 40 & 70 & 700 & 400 & 80 & 300 & 8000 & 500 \\
\hline $\mathrm{CON} A C, 60 \mathrm{~min}$ & \multicolumn{12}{|c|}{ no results, sample lost during digestion } \\
\hline
\end{tabular}

${ }^{1}$ Sample abbreviations: Biochar Solutions Incorporated (BSI), Tucker Engineering Associates (TEA), and Confluence Energy (CON).

\subsection{Adsorbent Properties}

Steam activation significantly improved the adsorbent properties of all three biochars (Table 7; Figure 3). Surface area improved from $177.3 \mathrm{~m}^{2} \mathrm{~g}^{-1}$ for the BSI biochar to $886.4 \mathrm{~m}^{2} \mathrm{~g}^{-1}$ for its resultant AC at the $45 \mathrm{~min}$ retention time. BSI biochar did not respond favorably to an additional $15 \mathrm{~min}$ in the calciner (Table 7; Figure 3). With surface area of $807.6 \mathrm{~m}^{2} \mathrm{~g}^{-1}$, the AC made from TEA biochar had a lower surface area than BSI AC at $45 \mathrm{~min}$, but responded favorably to $60 \mathrm{~min}$ in the calciner, which further increased its surface area to $1092.9 \mathrm{~m}^{2} \mathrm{~g}^{-1}$. It is worth nothing here that the low surface area of the TEA biochar $\left(2.0 \mathrm{~m}^{2} \mathrm{~g}^{-1}\right)$ is congruent with research on an earlier design of this system and is discussed in more detail in Section 4. AC from CON biochar had the lowest surface area of the three systems, at 744.8 and $729.7 \mathrm{~m}^{2} \mathrm{~g}^{-1}$ for the 45 and $60 \mathrm{~min}$ trials, respectively and, similar to the BSI biochar, the CON biochar showed a slight reduction in surface area with continued treatment at 60 min retention (Figure 3). These trends are reflected in the porosity and the iodine numbers of the biochar and AC samples (Table 7).

Table 7 uses the International Union of Pure and Applied Chemistry (IUPAC) pore size conventions: micropores are $<2.0 \mathrm{~nm}$, mesopores are $>2.0 \mathrm{~nm}$ but $<50 \mathrm{~nm}$, and macropores are $>50 \mathrm{~nm}$ [41]. All three biochars showed significant increases in micropore surface area following activation. However, BSI AC and CON AC had a lower proportion of their total surface area in micropores compared to their biochar precursors. In contrast, very little of 
the surface area of the TEA biochar was in the micropores compared to its resultant AC. The median pore diameter dropped from $9.454 \mathrm{~nm}$ for TEA biochar to $4.817 \mathrm{~nm}$ and $5.015 \mathrm{~nm}$ for TEA 45 and $60 \mathrm{~min}$ AC, respectively. Median pore diameter increased between biochar and $\mathrm{AC}$ at both activation levels for BSI and CON.

Table 7. Adsorption properties of the three biochars and their resultant activated carbon (AC) at two different calciner retention times of $45 \mathrm{~min}$ and $60 \mathrm{~min}$.

\begin{tabular}{|c|c|c|c|c|c|c|c|c|c|}
\hline \multirow{3}{*}{$\begin{array}{c}\text { Variable } \\
\text { Sample Type }\end{array}$} & \multicolumn{9}{|c|}{ Sample ${ }^{1}$} \\
\hline & \multicolumn{3}{|c|}{ BSI } & \multicolumn{3}{|c|}{ TEA } & \multicolumn{3}{|c|}{ CON } \\
\hline & Biochar & $\mathrm{AC}$ & AC & Biochar & $\mathrm{AC}$ & $\mathrm{AC}$ & Biochar & $\mathrm{AC}$ & $\mathrm{AC}$ \\
\hline Calciner Time (min) & 0 & 45 & 60 & 0 & 45 & 60 & 0 & 45 & 60 \\
\hline BET surface area $\left(\mathrm{m}^{2} \mathrm{~g}^{-1}\right)^{2}$ & 177.3 & 886.4 & 847.7 & 2.0 & 807.6 & 1092.9 & 289.1 & 744.8 & 729.7 \\
\hline $\begin{array}{l}\text { Micropore surface area } \\
\left(\mathrm{m}^{2} \mathrm{~g}^{-1}\right)\end{array}$ & 142.2 & 661.5 & 635.1 & $<0.01$ & 554.5 & 729.2 & 255.2 & 579.3 & 550.4 \\
\hline $\begin{array}{c}\text { Ratio of micropore to total } \\
\text { surface area }(\%)\end{array}$ & 80.2 & 74.6 & 74.9 & $<0.5$ & 68.7 & 66.7 & 88.3 & 77.8 & 75.4 \\
\hline Iodine number $\left(\mathrm{mg} \mathrm{g}^{-1}\right)$ & 352 & 979 & 1040 & 220 & 1015 & 1218 & 283 & 973 & 951 \\
\hline Total pore volume $\left(\mathrm{cc} \mathrm{g}^{-1}\right)$ & 0.1146 & 0.5912 & 0.5790 & 0.0069 & 0.6014 & 0.8393 & 0.1649 & 0.5061 & 0.4830 \\
\hline Porosity (fraction per g) & 0.1028 & 0.3715 & 0.3667 & 0.0069 & 0.3755 & 0.4563 & 0.1416 & 0.3360 & 0.3257 \\
\hline Avg pore diameter (nm) & 2.586 & 2.723 & 2.732 & 13.692 & 2.978 & 3.072 & 2.282 & 2.718 & 2.648 \\
\hline Median pore diameter $(\mathrm{nm})^{3}$ & 3.174 & 3.941 & 4.431 & 9.454 & 4.817 & 5.015 & 3.111 & 4.358 & 5.988 \\
\hline SD pore diameter $(\mathrm{nm})^{4}$ & 1.372 & 1.607 & 1.774 & 3.607 & 1.962 & 1.984 & 1.249 & 1.763 & 1.744 \\
\hline
\end{tabular}

${ }^{1}$ Abbreviations for activated carbon (AC) samples from biochar precursors produced by Biochar Solutions Incorporated (BSI), Tucker Engineering Associates (TEA), and Confluence Energy (CON). ${ }^{2}$ Brunauer-Emmet-Teller (BET) surface area. ${ }^{3}$ Based on pore volume. ${ }^{4}$ Standard deviation of pore diameter based on pore volume.

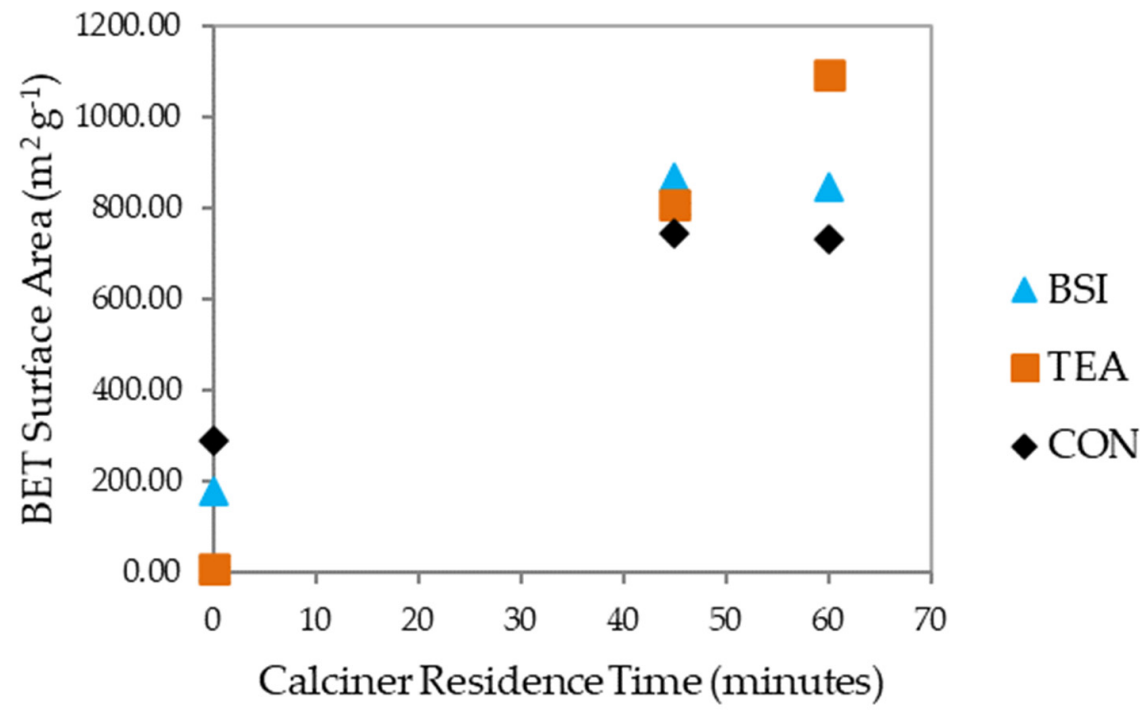

Figure 3. Surface area of biochars from Biochar Solutions Incorporated (BSI), Tucker Engineering Associates (TEA), and Confluence Energy (CON) and their resultant AC at two different calciner retention times of 45 and $60 \mathrm{~min}$.

\subsection{Microscopy}

Figure 4 shows SEM micrographs of five different AC at three different magnifications: $200 \times, 1000 \times$, and $5000 \times$. The physical structure of the three biochars, as observed under the SEM (not shown in Figure 4), showed less surface texture and less visible macropore area compared to their AC counterparts. At $200 \times$ magnification, the elongated fibrils of the wood were visible in the AC (Figure $4 \mathrm{a}, \mathrm{d}, \mathrm{g}$ ), with pits in the surface (seen as round holes) visible at $1000 \times$ and $5000 \times$ magnification in all three AC. The structure was notably similar 
across the three materials, even though they were produced using different pyrolysis systems with pine feedstocks from different sources. At $5000 \times$ magnification, the $5 \mu \mathrm{m}$ scale bar was equivalent to $5000 \mathrm{~nm}$, or about 100 times larger than the threshold diameter between macropores and mesopores. Though small pores were not visible in these images, it is clear that parts of the surface had been texturized and increased in surface area as a result. The AC made from coal (Figure 4j-1) and coconut shell (Figure $4 \mathrm{~m}-\mathrm{o}$ ) are also shown. The wood-derived AC had coarser and more uniform structure than coalbased AC, with better adsorption properties based on surface area, porosity, and iodine number. Micrographs of AC from coconut shell revealed a relatively uniform structure with systematically cross-linked fibrils separated by uniform pits.
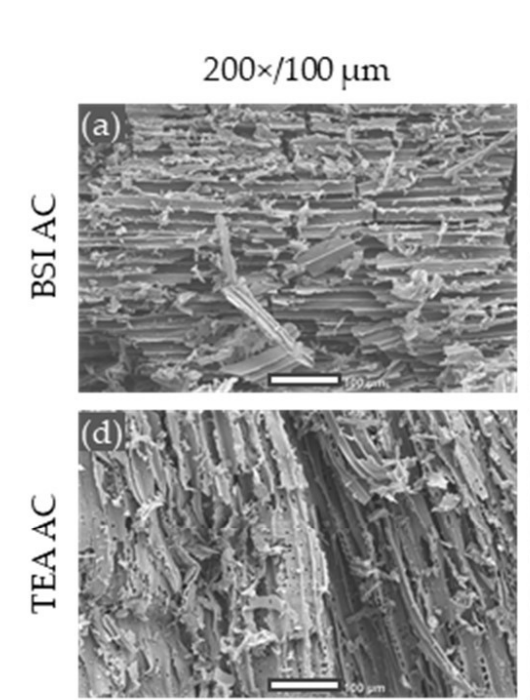

\section{Magnification}
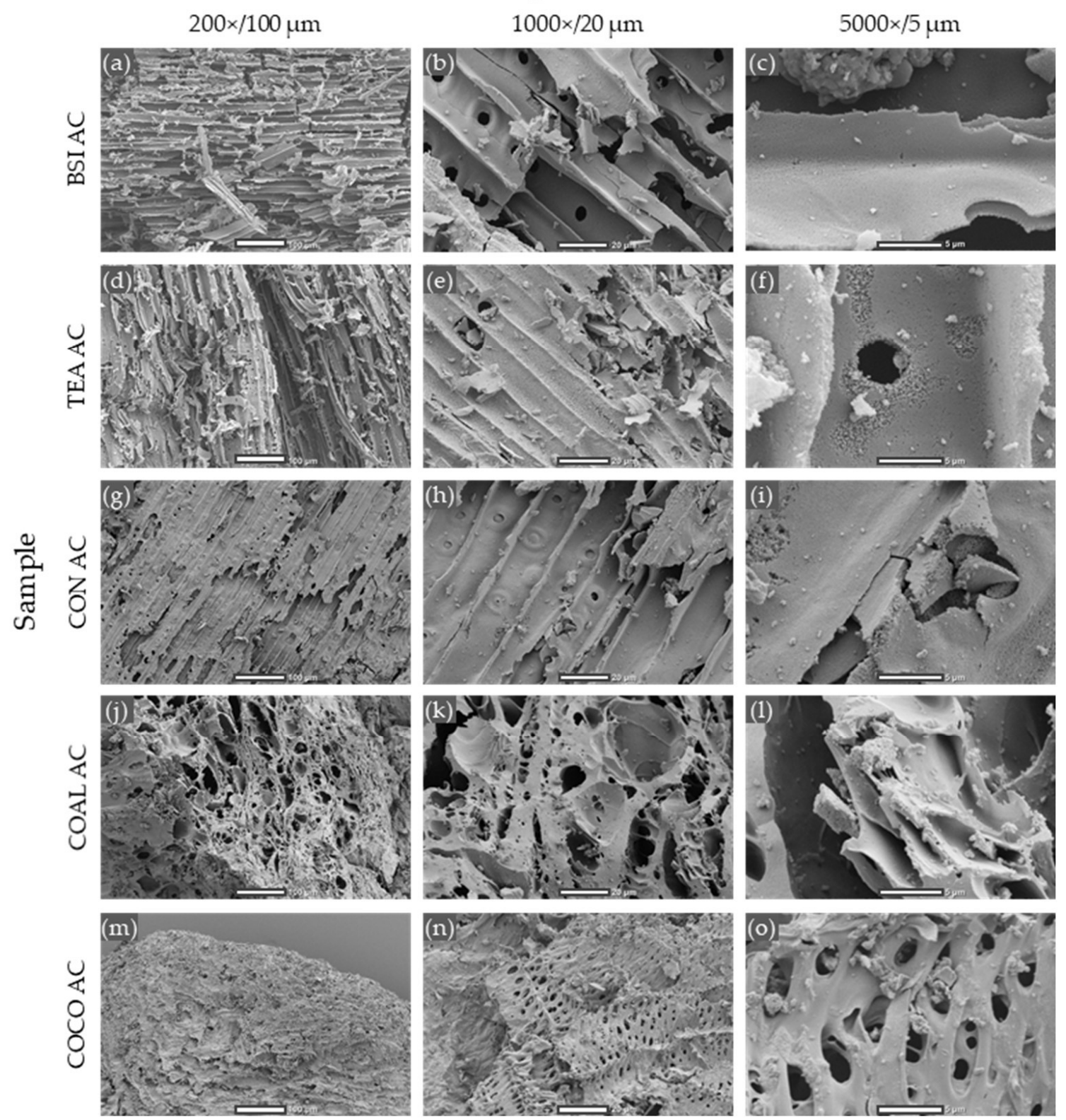

Figure 4. Scanning electron microscope micrographs for each of the five samples of activated carbon (AC) at three different magnifications: $200 \times, 1000 \times$, and 5000×. Three samples were activated in this study: Biochar Solutions Incorporated (BSI), Tucker Engineering Associates (TEA), and Confluence Energy (CON). Photographs of two other steam AC sold commercially for water filtering applications are included for reference, one from bituminous coal (COAL) and one from coconut shell (COCO). 


\section{Discussion}

Though notably different in their designs, the three pyrolysis systems produced biochars and AC from pine (Pinus spp.) feedstocks that were relatively similar in their physical and chemical characteristics. All three had similar particle size distributions and bulk density, and varied somewhat in ash content, carbon content, and other properties (Table 4). In general, the carbon content and stability of these materials appears to be high, based on their molar $\mathrm{H}: \mathrm{C}_{\text {organic }}$ ratios, which would likely translate to good recalcitrance when used as a soil amendment.

These AC compare favorably to the two commercial AC products used as reference samples in this study. BET surface area and micropore surface area are shown in Figure 5. Though the AC from carbonized coconut shell and bituminous coal had notably different structures in their SEM micrographs (Figure 4), their surface areas were similar to the biochar AC. All three biochar AC had higher total surface area and higher micropore surface area than the coal AC at $665.9 \mathrm{~m}^{2} \mathrm{~g}^{-1}$ and $555.9 \mathrm{~m}^{2} \mathrm{~g}^{-1}$, respectively. COCO had the highest micropore surface area $\left(741.8 \mathrm{~m}^{2} \mathrm{~g}^{-1}\right)$, and the highest percentage of total surface area in micropores (95.6\%). This may be apparent in Figure 4o, where the surface of COCO AC appeared smooth at $5000 \times$ magnification, compared to the TEA AC in $4 \mathrm{f}$, for example. TEA AC had a similar micropore total surface area of $729.2 \mathrm{~m}^{2} \mathrm{~g}^{-1}$ at the $60 \mathrm{~min}$ retention time, but significant additional surface area in meso- and macropores, resulting in a higher total surface area of $1092.9 \mathrm{~m}^{2} \mathrm{~g}^{-1}$ (Figure 5).

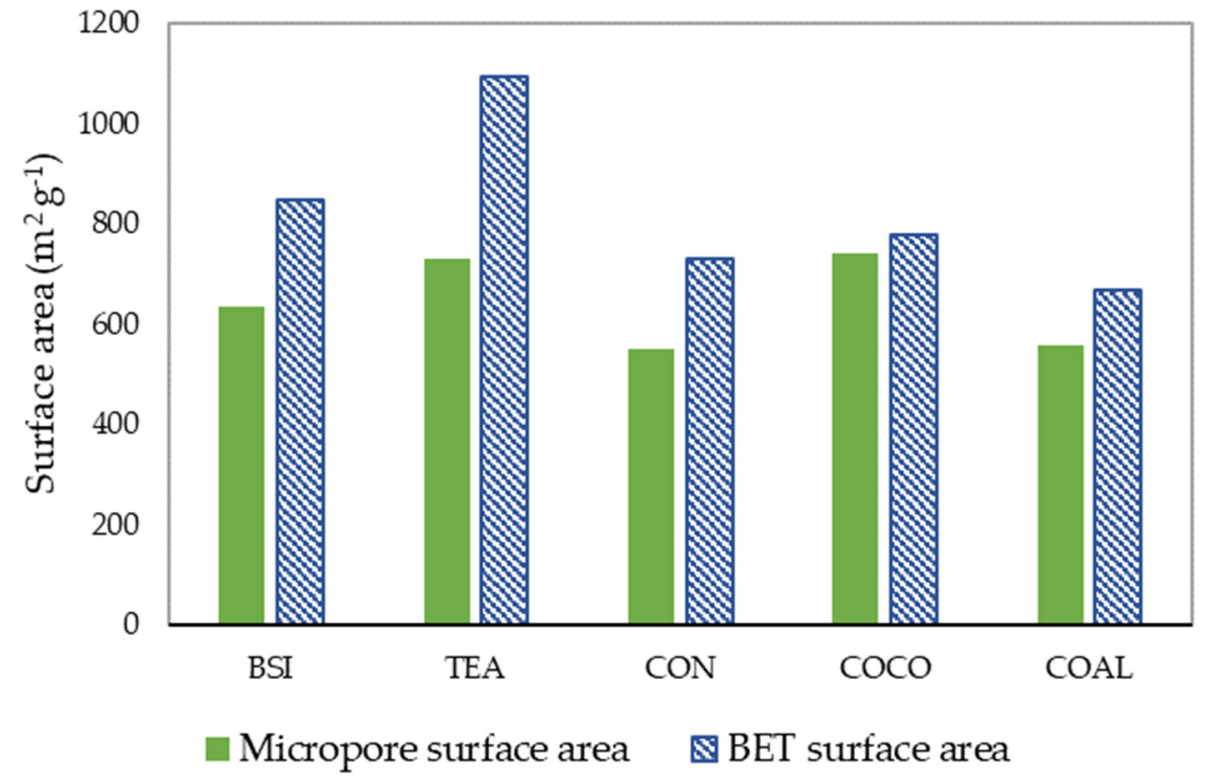

Figure 5. Comparison of micropore surface area to Brunauer-Emmet-Teller (BET) surface area for five activated carbon samples: Biochar Solutions Incorporated (BSI), Tucker Engineering Associates (TEA), Confluence Energy (CON), commercial AC from coconut shell (COCO) and commercial AC from hard coal (COAL).

TEA biochar had the lowest starting surface area and showed the most significant improvement in its adsorption properties following steam activation, with BET surface area increasing from 2.0 to $1092.9 \mathrm{~m}^{2} \mathrm{~g}^{-1}$ at the $60 \mathrm{~min}$ retention time (Table 7). Iodine number increased from 220 to $1218 \mathrm{mg} \mathrm{g}^{-1}$. The notably low biochar surface area is congruent with previous research using an earlier design of this system [32], showing a BET surface area of a similar biochar as $15.0 \mathrm{~m}^{2} \mathrm{~g}^{-1}$, which was activated to $1283.0 \mathrm{~m}^{2} \mathrm{~g}^{-1}$ using similar methods. In that case, the biochar was air cooled not water quenched, which implies that air cooled or water quenched TEA biochars respond similarly to steam activation.

Considering BET surface area and iodine number, TEA was the lowest performing biochar, but the highest performing AC of the three tested, comparing favorably to the AC from coconut shell, which had a BET surface area of $776.3 \mathrm{~m}^{2} \mathrm{~g}^{-1}$ and iodine number of 
$1223 \mathrm{mg} \mathrm{g}^{-1}$. Of the three AC derived from biochar, the TEA AC also showed positive response to longer calciner retention time (Figure 3), increasing from 807.6 to $1092.9 \mathrm{~m}^{2} \mathrm{~g}^{-1}$ between the $45 \mathrm{~min}$ and $60 \mathrm{~min}$ retention times. Micrographs in Figure 6 show the physical changes associated with the improvement in adsorptive properties. Figure $6 \mathrm{a}, \mathrm{b}$ show a notably smooth surface on the biochar compared to the textured surface of the AC in Figure $6 \mathrm{c}, \mathrm{d}$. The smooth surface of the biochar appeared to have responded well to steam. At $8000 \times$ magnification, the $2 \mu \mathrm{m}$ scale bar was equivalent to $2000 \mathrm{~nm}$, or about 40 times larger than the $50 \mathrm{~nm}$ diameter threshold between the macropores and mesopores.
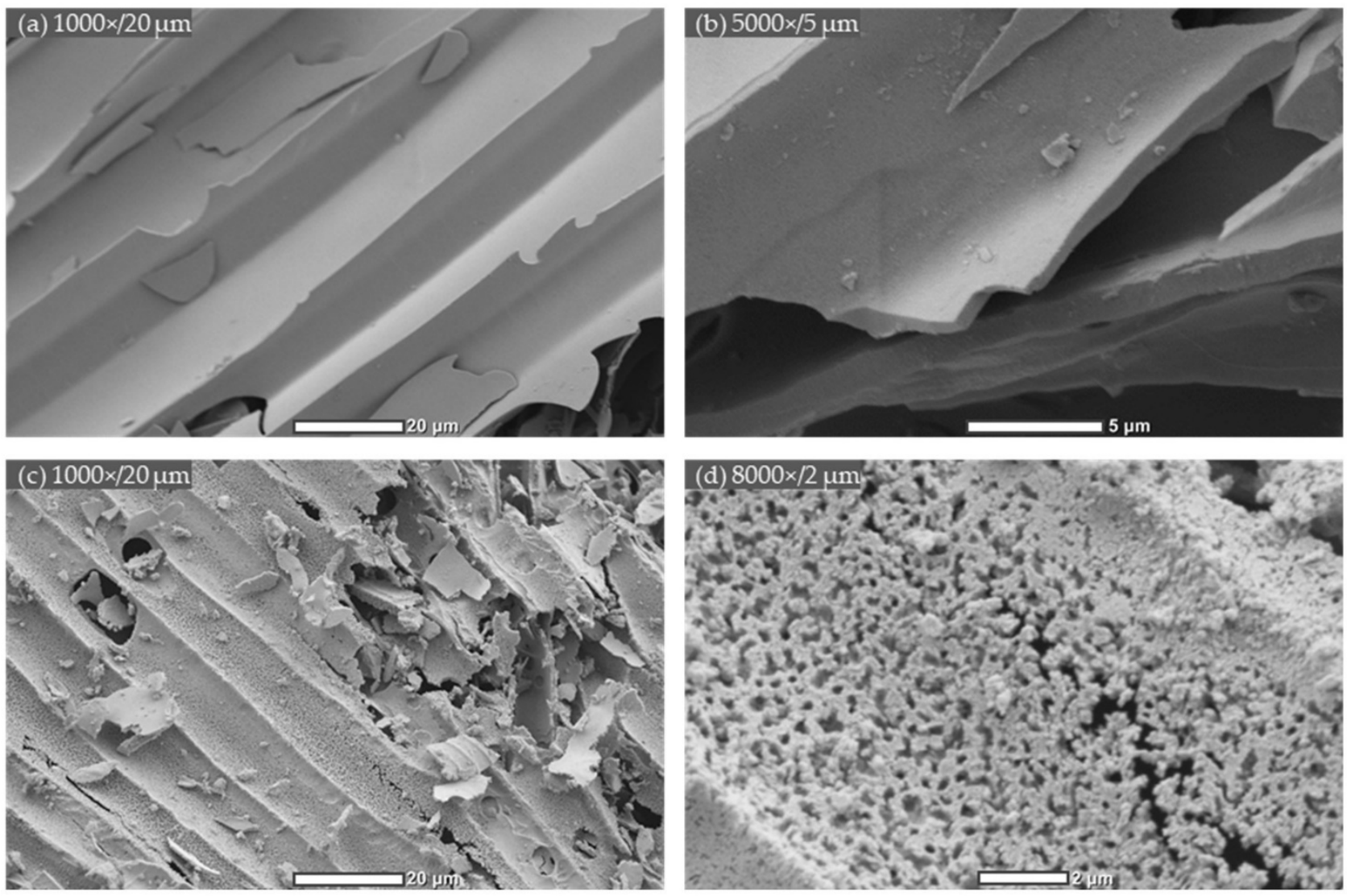

Figure 6. Scanning electron microscope micrographs of: (a) Tucker Engineering Associates (TEA) biochar, 1000 $\times$ magnification; (b) TEA bicochar, $5000 \times$ magnification; (c) activated carbon made from the TEA biochar, $1000 \times$ magnification; and (d) activated carbon made from the TEA biochar, $8000 \times$ magnification.

This case points toward the potential value of using high-temperature steam as a post-processing technique for biochar, even if the resultant material is not going to be used as AC. In this case, the properties of a high carbon wood biochar with low adsorptive capacity were improved significantly for uses that favor high surface area, porosity, and adsorptive capacity. From an operational standpoint, steam activation is likely to be a more attractive option than chemical activation for biochar processing in the forest sector. Many large forest industry facilities produce steam to provide heat for lumber drying and other manufacturing processes. Wood bioenergy systems are common, and the milling by-products and residues found at these facilities are suitable feedstocks for pyrolysis. In contrast, mills do not typically have the systems or the expertise required for chemical activation such as impregnation of wood feedstocks with dehydrating oxidants such as $\mathrm{H}_{3} \mathrm{PO}_{4}, \mathrm{ZnCL}_{2}$, and $\mathrm{KOH}$, or the downstream washing and recovery of reagents from aqueous solution.

It is important to point out that this improvement in the biochar's adsorptive properties comes at a cost. Mass loss due to burn-off during the activation process can be 
significant. Though these trials were not designed to accurately measure burn-off, average mass loss including both burn-off and material handling loss was above $50 \%$. There is a clear trade-off between improving the product's quality for certain uses and reducing the amount of salable product. If the price of the upgraded product does not cover the cost of activation including both process costs and mass loss, value has been lost, not added, with the additional processing.

This points to broader limitations of the study that should be addressed in future research. This was an applied study working with pyrolysis systems that were being actively used in industrial settings to produce biochar as a primary product (BSI) or coproduct of electricity (TEA) and wood pellets $(\mathrm{CON})$. We used a rotary calciner designed for process testing and equipment engineering, specifically for designing large-scale high throughput calciners for heat treating industrial materials. There were some benefits to this approach, including moving from small-scale laboratory and prototype settings to something more closely resembling an industrial supply chain from the feedstock to the final product. However, due to time and resource constraints, we were not able to conduct controlled experiments at this scale that would have more fully informed process design. For example, additional retention times and replicates would have allowed us to develop statistical models for the relationships between retention time and surface area and other variables for these and comparable biochars. Similarly, we were limited in our laboratory testing. A more complete characterization of biochars and AC such as those conducted by Castiglioni et al. [12] is needed to understand the value of these products for the full range of adsorptive applications and markets. Rigorous testing in real-world settings would evaluate the inferences of performance made here based on surface area and other characteristics, and would add to the empirical underpinnings that must guide the use of biochar as an industrial sorbent and precursor. Investment in biochar systems will hinge on equally robust financial analysis. The authors are currently engaged in a range of studies focused on the technoeconomic and life cycle assessment of several different pyrolysis pathways and their products, which is building on the research presented here.

\section{Conclusions}

Biochar markets are growing, but remain relatively small compared to markets for activated carbon and other industrial adsorbents. It has been frequently proposed including by the authors $[15,16,32]$, that biochar can be used as an effective and potentially cost competitive substitute for these products or as a precursor in the manufacture of specialized sorbents, especially in cases where bio-based products are preferred over coal and mineral products because they have lower life cycle environmental impacts as measured by their carbon footprint [15]. This study showed strong response to steam activation from three biochars produced by three different pyrolysis systems from similar softwood feedstocks. From a technical perspective, steam activation has the potential to improve biochar properties for both soil amendment and non-soil uses including commercial quality AC. From the perspective of investors in biochar enterprises, the possibility of diversifying into complementary product markets with non-soil products such as AC helps reduce investment risk to maximize the economic value of biochars made from mill and forest residues. It also has the potential to grow the bioeconomy and expand opportunities for biochar production and use in a wide range of applications.

Author Contributions: Conceptualization, N.A. and R.B.; Methodology, N.A., R.B. and H.G.; Formal analysis, N.A., R.B. and H.G.; Fieldwork, N.A., R.B. and H.G.; Life cycle assessment, R.B. and H.G.; Data curation, N.A.; Writing—original draft preparation, N.A.; Writing-review and editing, N.A., R.B. and H.G.; Writing-revisions following review, N.A.; Tables and figures, N.A.; Project administration, N.A.; Funding acquisition, N.A. and R.B. All authors have read and agreed to the published version of the manuscript.

Funding: This project was supported by the Agriculture and Food Research Initiative (AFRI) competitive grant number 2011-10006-30357 (Biomass Research and Development Initiative) and competitive 
grant number 2013-68005-21298 (Bioenergy Alliance Network of the Rockies) from the U.S. Department of Agriculture National Institute of Food and Agriculture (USDA-NIFA).

Institutional Review Board Statement: Not applicable.

Informed Consent Statement: Not applicable.

Data Availability Statement: Most of the primary data collected in this study are provided in the tables and figures. Some additional data not included here, such as concentrations of some low concentration elements that were omitted to simplify the tables, are available upon request from the corresponding author.

Acknowledgments: The authors are extremely grateful to Bradd Thomas, Jonah Levine, and Richard Tucker, without whom this research would not have been possible. Thanks to Debbie Page-Dumroese for her consultation on soil science and other aspects of biochar use, and to Kolby Hirth at the U.S. Forest Service, Forest Products Laboratory, for ICO-OES elemental analysis. Van Morris, Brad Dunmire, and Mark Mathis provided consultation and additional information used in this study. The authors would also like to thank several laboratories for assistance with analyzing feedstocks, biochar, and activated carbon samples including: Hazen Research, Inc.; ARVOS Group; Professional Analytical Consulting Services, Inc.; Particle Technology Labs; Porous Materials, Inc.; and Airtech Environmental Services. Acknowledgement of these companies here does not imply endorsement by the U.S. government.

Disclaimer: The authors of this paper are employees of the United States Department of Agriculture, U.S. Forest Service. The findings and conclusions in this report are those of the authors and should not be construed to represent any official USDA or U.S. Government determination or policy. This research was supported in part by the U.S. Department of Agriculture, Forest Service. Any use of trade, firm, or product names is for descriptive purposes only and does not imply endorsement by the U.S. government.

Conflicts of Interest: The authors declare no conflict of interest. The funders of this study and industry partners providing biochar had no role in the collection, analyses, or interpretation of data; in the writing of the manuscript, or in the decision to publish the results.

\section{References}

1. Dumroese, R.K.; Page-Dumroese, D.; Pinto, J. Biochar potential to enhance forest resilience, seedling quality, and nursery efficiency. Tree Plant. Notes 2020, 63, 61-68.

2. Lehmann, J.; Joseph, S. Biochar for environmental management: An introduction [Chapter 1]. In Biochar for Environmental Management; Lehman, J., Joseph, S., Eds.; Earthscan: London, UK, 2009; p. 448.

3. Anderson, N.; Bergman, R.; Page-Dumroese, D. A supply chain approach to biochar systems [Chapter 2]. In Biochar: A regional Supply Chain Approach in View of Climate Change Mitigation; Bruckman, V., Varol, E., Uzun, B., Liu., J., Eds.; Cambridge University Press: Cambridge, UK, 2017; pp. 25-45.

4. Yan, J.; Oyedeji, O.; Leal, J.H.; Donohoe, B.S.; Semelsberger, T.A.; Li, C.; Hoover, A.N.; Webb, E.; Bose, E.A.; Zeng, Y.; et al. Characterizing Variability in Lignocellulosic Biomass: A Review. ACS Sustain. Chem. Eng. 2020, 8, 8059-8085. [CrossRef]

5. $\mathrm{Hu}, \mathrm{X}$.; Gholizadeh, M. Biomass pyrolysis: A review of the process development and challenges from initial researches up to the commercialization stage. J. Energy Chem. 2019, 39, 109-143. [CrossRef]

6. Dhyani, V.; Bhaskar, T. Pyrolysis of biomass. [Chapter 9]. In Biofuels: Alternative Feedstocks and Conversion Processes for the Production of Liquid and Gaseous Biofuels; Pandey, A., Larroche, C., Dussap, C., Gnansounou, E., Khanal, S., Ricke, S., Eds.; Elsevier Academic Press: London, UK, 2019; pp. 217-244.

7. Cha, J.S.; Park, S.H.; Jung, S.-C.; Ryu, C.; Jeon, J.-K.; Shin, M.-C.; Park, Y.-K. Production and utilization of biochar: A review. J. Ind. Eng. Chem. 2016, 40,1-15. [CrossRef]

8. Panahi, H.K.S.; Dehhaghi, M.; Ok, Y.S.; Nizami, A.-S.; Khoshnevisan, B.; Mussatto, S.I.; Aghbashlo, M.; Tabatabaei, M.; Lam, S.S. A comprehensive review of engineered biochar: Production, characteristics, and environmental applications. J. Clean. Prod. 2020, 270, 122462. [CrossRef]

9. Tomczyk, A.; Sokołowska, Z.; Boguta, P. Biochar physicochemical properties: Pyrolysis temperature and feedstock kind effects. Rev. Environ. Sci. BioTechnol. 2020, 19, 191-215. [CrossRef]

10. International Biochar Initiative (IBI). Standardized Product Definition and Product Testing Guidelines for Biochar That Is Used in Soil, IBI Biochar Standards, Version 2.1; International Biochar Initiative: Canandaigua, NY, USA, 2015; p. 61. Available online: https:/ / biochar-international.org/ characterizationstandard/ (accessed on 2 November 2021).

11. European Biochar Foundation. European Biochar Certificate (EBC)-Guidelines for a Sustainable Production of Biochar, Version 8.3E. September 2019; European Biochar Foundation: Arbaz, Switzerland, 2012; p. 36. Available online: http://www.europeanbiochar. $\mathrm{org} / \mathrm{en} /$ download (accessed on 2 November 2021). 
12. Castiglioni, M.; Rivoira, L.; Ingrando, I.; Meucci, L.; Binetti, R.; Fungi, M.; El-Ghadraoui, A.; Bakari, Z.; Del Bubba, M.; Bruzzoniti, M.C. Biochars intended for water filtration: A comparative study with activated carbons of their physicochemical properties and removal efficiency towards neutral and anionic organic pollutants. Chemosphere 2022, 288, 132538. [CrossRef] [PubMed]

13. Inyang, M.I.; Gao, B.; Yao, Y.; Xue, Y.; Zimmerman, A.; Mosa, A.; Pullammanappallil, P.; Ok, Y.S.; Cao, X. A review of biochar as a low-cost adsorbent for aqueous heavy metal removal. Crit. Rev. Environ. Sci. Technol. 2016, 46, 406-433. [CrossRef]

14. Mohan, D.; Sarswat, A.; Sik Ok, Y.; Pittman, C., Jr. Organic and inorganic contaminants removal from water with biochar, a renewable, low cost and sustainable adsorbent-A critical review. Bioresour. Technol. 2014, 160, 191-202. [CrossRef] [PubMed]

15. Gu, H.; Bergman, R.; Anderson, N.; Alanya-Rosenbaum, S. Life cycle assessment of activated carbon from woody biomass. Wood Fiber Sci. 2018, 50, 229-243. [CrossRef]

16. Bergman, R.; Gu, H.; Alanya-Rosenbaum, S.; Liang, S. Comparative Life-Cycle Assessment of Biochar Activated Carbon and Synthesis Gas Electricity with Commercially Available Alternatives; Gen. Tech. Rep. FPL-GTR-270; U.S. Department of Agriculture, Forest Service, Forest Products Laboratory: Madison, WI, USA, 2019; pp. 1-32.

17. Bubanale, S.; Shivashankar, M. History, method of production, structure and applications of activated carbon. Int. J. Eng. Res. Technol. 2017, 6, 495-499.

18. Hagemann, N.; Spokas, K.; Schmidt, H.; Kagi, R.; Bohler, M.; Bucheli, T. Activated carbon, biochar and charcoal: Linkages and synergies across pyrogenic carbon's ABCs. Water 2018, 10, 182. [CrossRef]

19. Lewis, W.K.; Metzner, A.B. Engineering, design and process development section: Activation of carbons. Ind. Eng. Chem. 1954, 46, 849-858. [CrossRef]

20. Heidarinejad, Z.; Dehghani, M.; Heidari, M. Methods for preparation and activation of activated carbon: A review. Environ. Chem. Lett. 2020, 18, 393-415. [CrossRef]

21. González-García, P. Activated carbon from lignocellulosics precursors: A review of the synthesis methods, characterization techniques and applications. Renew. Sustain. Energy Rev. 2018, 82, 1393-1414. [CrossRef]

22. Nor, N.; Lau, L.; Lee, K.; Mohamed, A. Synthesis of activated carbon from lignocellulosic biomass and its applications in air pollution control-A review. J. Environ. Chem. Eng. 2013, 1, 658-666.

23. Wang, X.; Cheng, H.; Ye, G.; Fan, J.; Yao, F.; Wang, Y.; Jiao, Y.; Zhu, W.; Huang, H.; Ye, D. Key factors and primary modification methods of activated carbon and their application in adsorption of carbon-based gases: A review. Chemosphere 2022, 287, 131995. [CrossRef] [PubMed]

24. Hilber, I.; Bucheli, T. Activated carbon amendment to remediate contaminated sediments and soils: A review. Glob. NEST J. 2010, 12, 305-317.

25. Tseng, R.; Wu, F.; Juang, R. Liquid-phase adsorption of dyes and phenols using pinewood-based activated carbons. Carbon 2003, 41, 487-495. [CrossRef]

26. Ismadji, S.; Sudaryanto, Y.; Hartono, S.; Setiawan, L.; Ayucitra, A. Activated carbon from char obtained from vacuum pyrolysis of teak sawdust: Pore structure development and characterization. Bioresour. Technol. 2005, 96, 1364-1369. [CrossRef] [PubMed]

27. Açıkyıldız, M.; Gürses, A.; Karaca, S. Preparation and characterization of activated carbon from plant wastes with chemical activation. Microporous Mesoporous Mater. 2014, 198, 45-49. [CrossRef]

28. Danish, M.; Ahmad, T. A review on utilization of wood biomass as a sustainable precursor for activated carbon production and application. Renew. Sustain. Energy Rev. 2018, 87, 1-21. [CrossRef]

29. Integration of Biofuels and Bioproducts Production into Forest Products Supply Chains Using Modular Biomass Gasification and Carbon Activation; Project MONW-2010-05325; USDA, National Institute of Food and Agriculture: Washington, DC, USA, 2011. Available online: https:/ / portal.nifa.usda.gov / web / crisprojectpages /0225135-integration-of-biofuels-and-bioproducts-production-intoforest-products-supply-chains-using-modular-biomass-gasification-and-carbon-activati.html (accessed on 2 December 2021).

30. Idaho National Laboratory. Bioenergy Feedstock National Library; Idaho National Laboratory: Idaho Falls, ID, USA, 2021. Available online: https:/ / bioenergylibrary.inl.gov/Home/Home.aspx (accessed on 2 November 2021).

31. Kim, D.; Anderson, N.; Chung, W. Financial performance of a mobile pyrolysis system used to produce biochar from sawmill residues. For. Prod. J. 2015, 65, 189-197. [CrossRef]

32. Anderson, N.; Jones, J.G.; Page-Dumroese, D.; McCollum, D.; Baker, S.; Loeffler, D.; Chung, W. A comparison of producer gas, biochar, and activated carbon from two distributed scale thermochemical conversion systems used to process forest biomass. Energies 2013, 6, 164-183. [CrossRef]

33. Gu, H.; Bergman, R. Life-cycle assessment of a distributed-scale thermochemical bioenergy conversion system. Wood Fiber Sci. 2016, 48, 129-141.

34. Gu, H.; Bergman, R. Cradle-to-grave life cycle assessment of syngas electricity from woody biomass residues. Wood Fiber Sci. 2017, 49, 177-192.

35. Campbell, R.; Anderson, N.; Daugaard, D.; Naughton, H. Technoeconomic and policy drivers of project performance for bioenergy alternatives using biomass from beetle-killed trees. Energies 2018, 11, 293. [CrossRef]

36. Sahoo, K.; Bilek, E.; Bergman, R.; Mani, S. Techno-economic analysis of producing solid biofuels and biochar from forest residues using portable systems. Appl. Energy 2019, 235, 578-590. [CrossRef]

37. Fungai, N.; Mukome, D.; Zhang, X.; Silva, L.; Six, J.; Parikh, S. Use of Chemical and Physical Characteristics To Investigate Trends in Biochar Feedstocks. J. Agric. Food Chem. 2013, 61, 2196-2204. 
38. Campbell, R.; Anderson, N.; Daugaard, D.; Naughton, H. Financial viability of biofuel and biochar production from forest biomass in the face of market price volatility and uncertainty. Appl. Energy 2018, 230, 330-343. [CrossRef]

39. Wright, L.; Boundy, B.; Badger, P.; Perlack, B.; Davis, S. Biomass Energy Data Book, 2nd ed.; U.S. Department of Energy, Oak Ridge National Laboratory: Oak Ridge, TN, USA, 2009; p. 224.

40. Krook, J.; Mårtensson, A.; Eklund, M. Sources of heavy metal contamination in Swedish wood waste used for combustion. Waste Manag. 2006, 26, 158-166. [CrossRef] [PubMed]

41. International Union of Pure and Applied Chemistry (IUPAC). Compendium of Chemical Terminology, 2nd ed.; McNaught, A.D., Wilkinson, A., Eds.; Online Version (2019) Created by Chalk, S.J.; Blackwell Scientific Publications: Oxford, UK, 1997; Available online: https:/ / doi.org/10.1351/goldbook (accessed on 2 November 2021). 